\title{
Analysis on the Technology Characteristic of a New Kind of Assembly Steel Frame System
}

\author{
Z. H. Zhang and X. P. Shu
}

\begin{abstract}
Assembly steel frame system, widely used in lower storey and multi-storey buildings, is suitable for modular construction. But in high-rise building, it is rarely applied. In this paper, a new kind of assembly truss beam steel frame system is proposed. The composition of the system, the technology characteristic of components and connections are analyzed in detail. Meanwhile the technology superiority and some problems need to be solved are also put forward.
\end{abstract}

Index Terms-Steel frame, assembly steel frame system, modular construction, technology characteristic.

\section{INTRODUCTION}

With the requirement of building industrialization, factory prefabrication and assembly construction of building blocks are taken as the development direction of building industry in the developed country, and the assembly structure system has been used extensively. The steel structure has the characteristic of easy rebuilding and removing, and high material recovery rate, as a kind of green building, which is the most suited structure type for prefabricated building [1]-[3]. At present, the steel structure system suitable for the low-multi-story building is the main stream for the assembly steel structural system, which has already owned very perfect technical system and abundant auxiliary products and formed a ripe industry chain, but for multi-high rise structure, the kind of fabricated structure is relatively few [4]. So this paper introduces one kind of new assembly steel-frame system suitable for multi-high rise buildings, which summarizes and analyzes the main technical characteristics and advantages of the structure system, at the same time some unsettled problems related with popularization and application are pointed out.

\section{PROCEDURE FOR PAPER SUBMISSION}

Considering the function different of structure components, the structure system can be split into two parts:

1) Main structural frame

2) Envelope structure

\section{A. The Main Structural Frame System}

The main structural frame system insists of stand column, brace, floor system and foundation. The stand column adopts

Manuscript received January 3, 2014; revised March 12, 2014. This work was supported by the Science and Technology Planning Project of YiYang (No.2013JZ12),

The authors are with the Steel Structural Institute of Civil Engineering College, Hunan University, Changsha, China (e-mail: zaihua_zhang@ 163.com, shuxingping@sina.com). square hollow section (SHS) column and the inclined bracing is comprised of C-type steel, while the beam adopts truss beam, which is called assembly truss beam steel structure system. The system can apply to the multi-high rise steel buildings below $100 \mathrm{~m}$ ( 30 floors). Considering the requirement of standardized production, it is divided into three sections according to the structure level number. No. 1 section used for 1th-10th storey building, No. 2 section used for 11 th-20th storey building, and No. 3 section used for 21 th-30th storey building. The overall structure arrangement is shown in Fig. 1. Fig. 2 indicates a typical structure unit of factory pre-assembly and Fig. 3 indicates the site assembly situation in a pilot project.

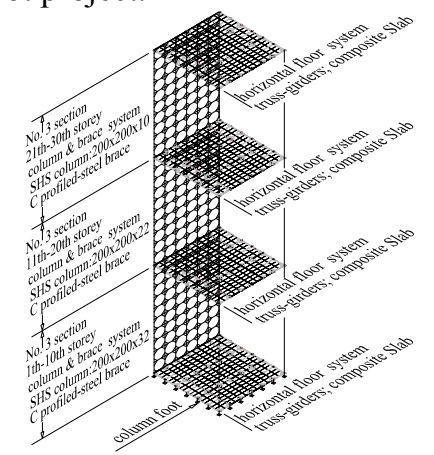

Fig. 1. Overall structure arrangement of assembly truss beam steel frame system.

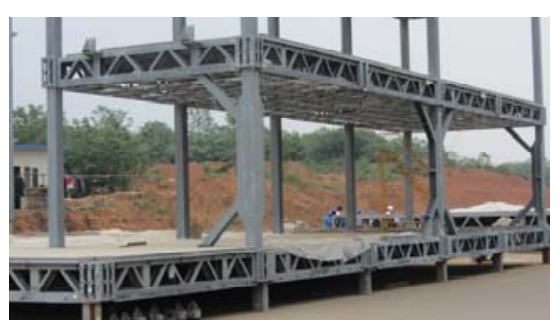

Fig. 2. Typical structure unit of pre-assembly.

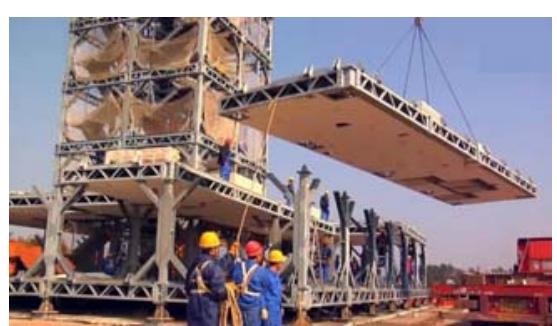

Fig. 3. Assembly process in building site.

\section{B. The Envelope Structure}

The envelope structure includes Internal and External wall system, Windows \& Doors system.

Fig. 4 shows a typical detail of the internal wall unit. It is a kind of light steel keel double-side gypsum board, which is filled with Sound-absorbing Sponge. Light, fireproofing and easy to disassembled are the main features of such a wall 
system.

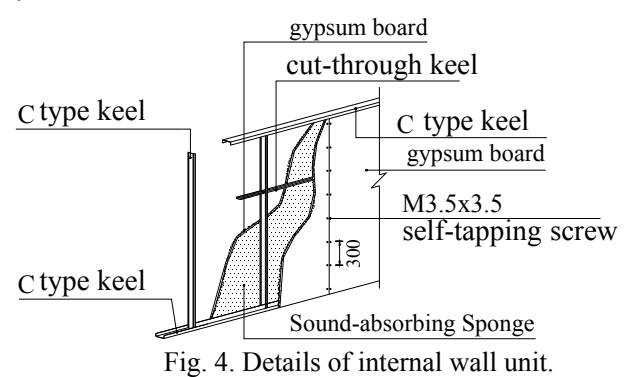

There are two kinds of configuration forms for the external wall system: one is the combination of high performance steel plate and rock wool, the other is the combination of glass curtain wall and rock wool (as is shown in Fig. 5 and Fig. 6). They are pre-fabricated as basic assemblies unite in factory and connected to the truss beam with bolts in construction site. The low thermal conductivity, good durable performance and high installation efficiency are the main characteristic of the external wall system.

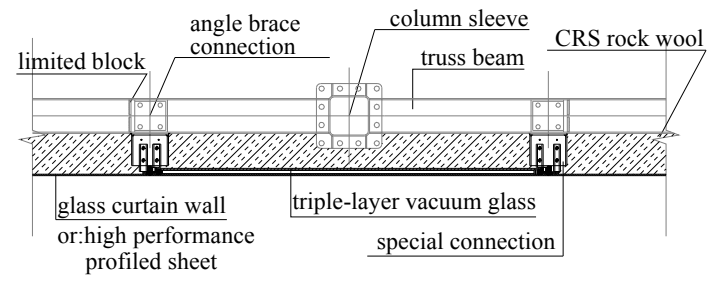

Fig. 5. Details of external wall unit.

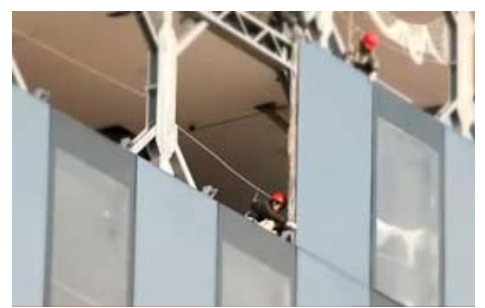

Fig. 6. Installation of external wall unit.

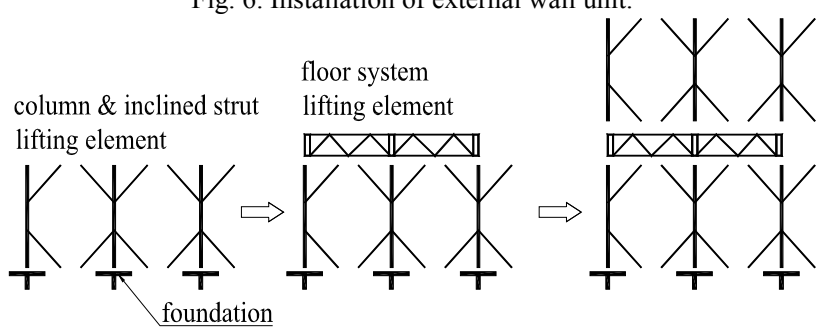

Fig. 7. The process of assembly floor by floor.

\section{The MaIn TECHNICAL ChARACTERISTIC FOR THE Assembly TRuss Beam Steel Frame System}

\section{A. Assembling Columns Floor by Floor and Modular Prefabrication of Floor Slab Units}

In this structure system, frame column of each storey is a disconnected unit. The column and C-type steel inclined brace of each storey are integrated to an assembly unit, meanwhile truss beam of floor and steel deck concrete composite slabs are integrated to the other assembly unit in the factory. The two hoisting units are assembled floor-by-floor in order. After the base floor system is finished, it naturally becomes the operation platform for assembling the upper storey. Such a layering assembly way like building block (Fig. 7) not only effectively reduces the high-altitude operation but also greatly improves the safety and construction efficiency.

One basic requirement of industrialized building is the design and production standardization of all components. In the structure system of assembly truss beam steel-frame, the columns of each section share the same cross profile meanwhile columns of each storey are disconnected into an independent unit. The column and C-type steel inclined brace can easily realize standardized production. In order to give full play to the advantage of factory production, modularized design is adopted in the design of floor system. By this means, the type of component (especially for beam) is limited during the plane arrangement of structural system. In the system $3900 \mathrm{~mm}$ is adopted as the basic module and different building plane types are formed through module combination. Fig. 8 indicates the two basic plate types in the system that the max span of plate unit is $7.8 \mathrm{~m}$. Fig. 9 shows several usual plane combination types. Among these combinations the types of main truss beam are 2 kinds and the type of assembled truss beam is one kind, which greatly facilitates the design, manufacturing and installment of the structure. (a) 1 \# floor unit

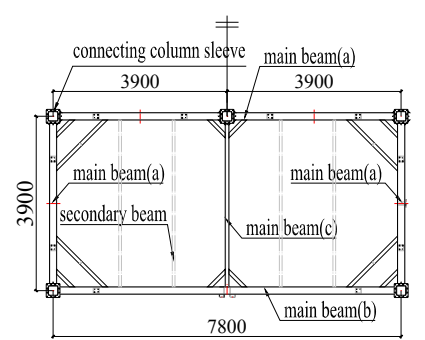

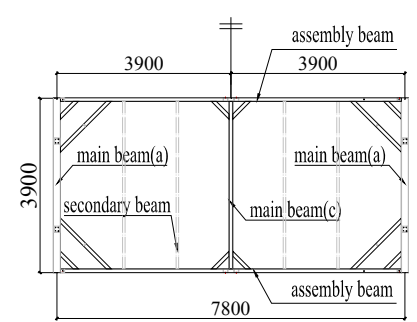

(b) 2 \# floor unit
Fig. 8. The form of floor basic unit.
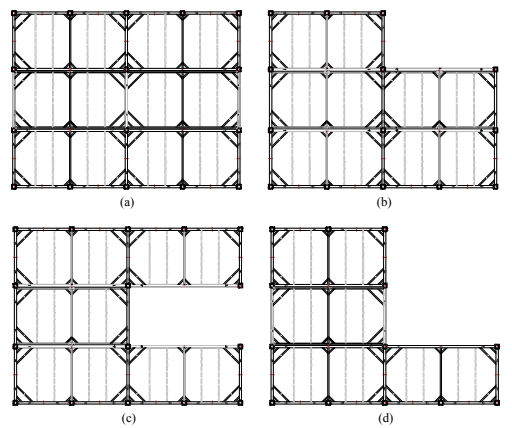

Fig. 9. The scheme of floor unit combination.

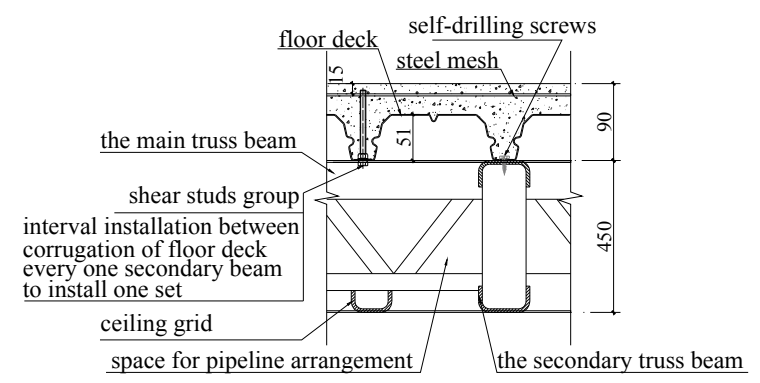

Fig. 10. Construction of integrated floor, ceiling and pipeline system.

In the assembly unit of truss beam and floor slab, the upper and lower chords of truss beam are cold-formed channel while its web member is hot-rolled angle steel. The floor slab is steel sheet-concrete composite floor which is connected to upper chord member of truss beam through shear studs. In the 
position of lower chord plane, the ceiling system is assembled. Meanwhile the open-frame truss beam provides the arrangement of related pipeline with space. The basic configuration of floor slab is shown as Fig. 10 which is a kind of prefabricated part with high function integration. Fig. 11 shows the factory construction process.

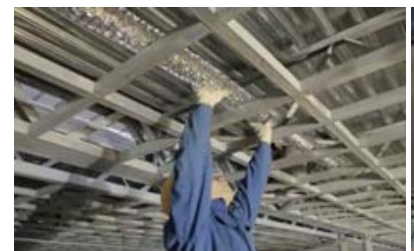

(a) pipeline installation

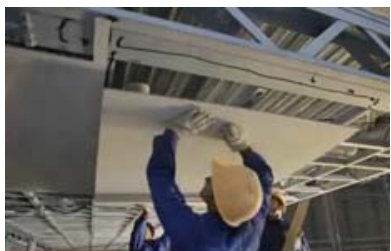

(b) ceiling installation
Fig. 11. Factory production of integrated floor, ceiling and pipeline system.

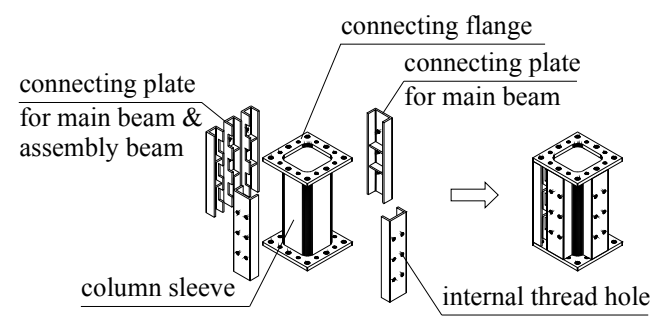

(a) decomposition graph of column-sleeve.

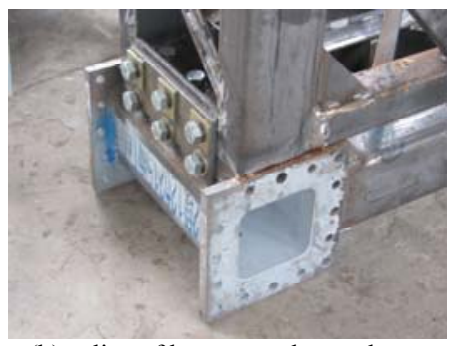

(b) splice of beam to column-sleeve

Fig. 12. Basic structure schematic of column-sleeve.

\section{B. Semi-Rigid Sleeve-Flange Connection of Beam-Column}

The special designed beam-column connection way is a key factor for the realization of structure assembly, which guarantees the structure performance. Fig. 12 shows the basic details of the connection as is called column base, one kind of connecting sleeve with flange plate. The forming process of the connection is shown as Fig. 13. The column sleeve is SHS column. The size of external profile is the same with frame column's, whose upper and lower sides are both welded with flange plate. Fig. 13(1) indicates the connection way of column sleeve and truss beam. The reversed channel steel is welded to column sleeve, and an enclosed channel steel is installed on the end of truss beam as well, then the two parts are connected through high-strength bolt to form a joint construction like end-plate connection. The assembly method of prefabricated-shaped floor and frame column is shown in Fig. 13 (2). The top and bottom of the column are both fixed the corresponding connecting flange to that of column sleeve, and the column plugs are also set [5] (Fig. 14). At the side of fixing assembly beam, a partial extension of flange plate is set to support the assembly beam and the cantilever plate is assembled with limiting pin to assist the floor plate in locating. The flange plate of frame column and that of column sleeve are connected by high-strength bolts on spot, which can easily realize the assembly of the whole structural system floor by floor. Such a kind of connection not only

satisfies the requirement of standardized production but also has a good mechanical performance. It can connect the truss beam to frame column reliably and satisfy the design idea of "strong-joint and weak-member" [6].

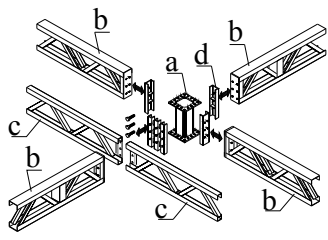

(1) splice of struss to column sleeve

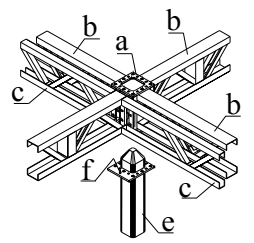

(2) splice of floor system to column

Fig. 13. Forming process of beam-to-column connection. (A-column sleeve; b- main girder; c-assembly beam; d- Connection angle; e-SHS column; f- limiting pin)
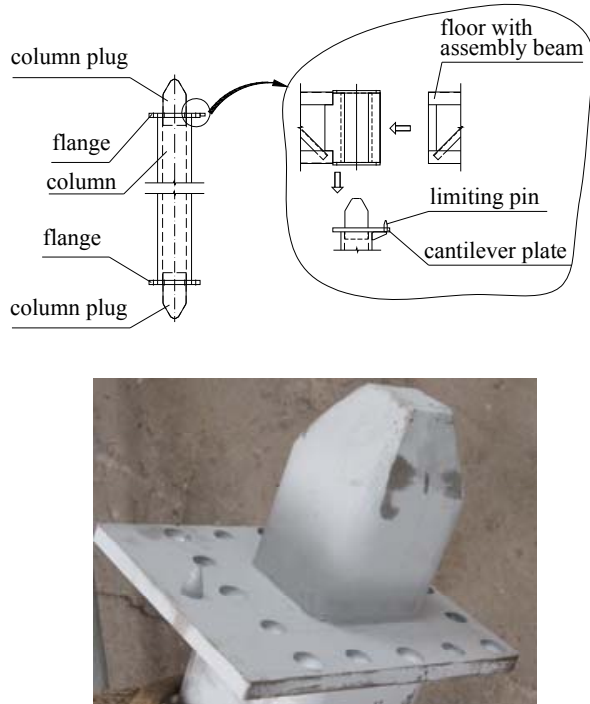

Fig. 14. Details of the end flange and plug of column.
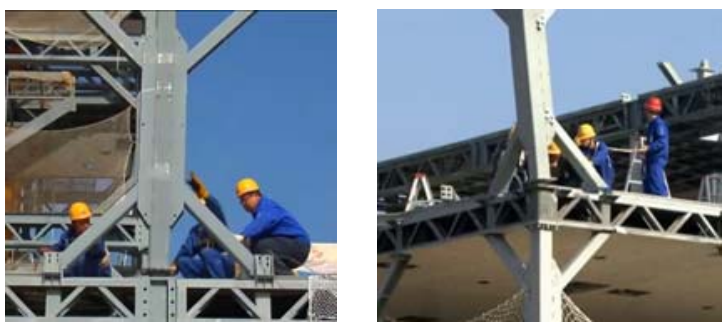

Fig. 15. Field installation of column-brace hoisting unit.

\section{Continuous Arrangement of Cold-Formed Channel} Angle Brace

The structural system is a kind of braced frame system, set with a special type of brace. The section of brace is channel, adopting the same shaping way as the chord member of floor's truss beam which is cold roll forming of steel plate. One side of the brace is connected to truss beam and the other side is connected to frame column, which forms the angle brace. The arrangement form of brace is different from the usual angle brace's:

1) In the position of structural outer wall, the upper and lower chords of truss beam are installed with braces simultaneously. The angle brace and the frame column are assembled into one hoisting unit in factory firstly forming a sort of brace-column combination (Fig. 15). Then they will be transported to the spot and installed into one kind of continuous layout angle-brace steel frames (Fig. 16). 
2) Inside the structure, the brace is arranged in an appropriate position according to the design requirement. Such a kind of arrangement not only guarantees the mechanical performance of the structure but also supplies maximal usage space for interior.
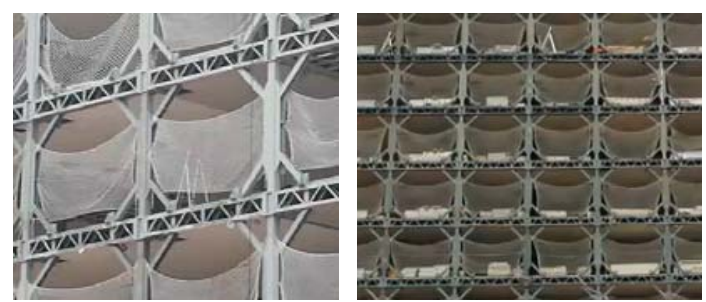

Fig. 16. Arrangement of peripheral frame support.

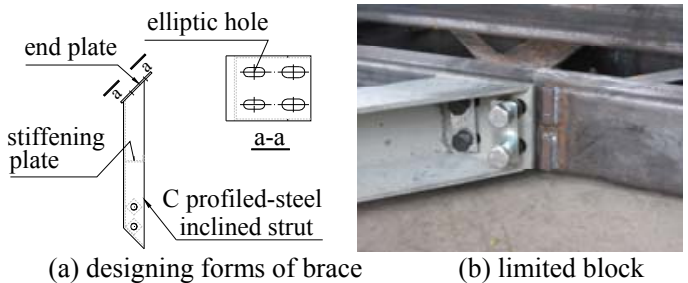

(a) designing forms of brace (b) limited block

Fig. 17. Details of brace-beam connection.

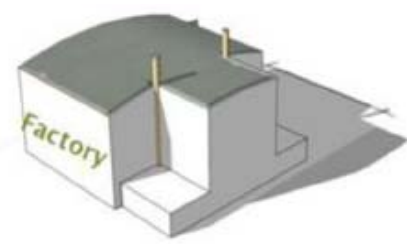

(a) components construction in factory.

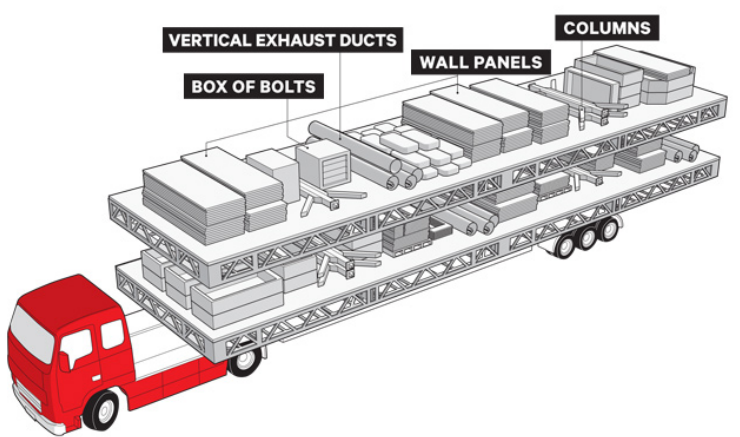

(b) delivery of components
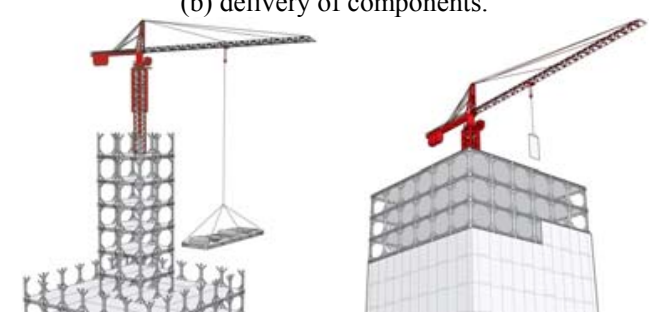

(c) assembly of main structure (d) assembly of envelope structure

Fig. 18. Construction process of the structure system.

For the field assembly of the structural system, besides above statement sleeve-flange connections, another important splice joint is the connection of brace to truss beam. The design form of brace is shown in Fig. 17 (a). In order to facilitate the field assembly, a group of oval hole is set up on the end-plate connecting the brace and truss beam, meanwhile a limited block is located close to the assembly position of angle brace (Fig. 17(b)). Such a connection detail offers great convenience for the location and fabrication of joint on spot, meanwhile it possesses good performance of friction energy dissipation under large earthquake [7], [8].

D. High Modular Construction for the Production and Assembly of Structure System

Basing on the several main technical characteristics mentioned above, the truss beam steel frame system can achieve high modular construction. More than $90 \%$ of construction works such as production of column-brace units, floor slab units and envelope structure can be finished in factory. The work efficiency of on-site fabrication is very high. Fig. 18 shows the construction process for modular construction method.

\section{The TeChNological Superiority of THE NeW KIND OF STRUCTURAL SYSTEM}

The assembly truss beam steel frame system is a kind of new-type multi-high rise steel structure system. Comparing to the traditional steel frame system, it owns obvious technical advantages, and is a promising structure system.

\section{A. The Degree of Factory Production and Functional Integration is High, and the Spot Installs of Components is Convenience}

In this structure system, all components are pre-fabricate in the factory, assembled with high strength bolts and almost no welding in spot, which improves the construction efficiency greatly. The integration degree of two kinds of hoisting unit is very high. Using the approach of factory production and integration assembly, the traditional industry manufacturing technology can be applied to the building industry which makes the quality guarantee more reliably.

\section{B. The Redundancy of Whole Structure is High and the Anti-Seismic Performance of Structure is Good}

Because of adoption standardized production, the sectional dimension of many components is uniform. Comparing the traditional structures which need optimal design, the kind of assembly structure system owns bigger redundancy and higher safety factor. Especially due to the arrangement of new type of angle brace, it not only has no effect on the use of building space but also greatly improves the total rigidity of the whole system, the structure system has good seismic performances.

\section{The Application Range of the System is Wide}

Through changing the plan combination mode of standardization prefabrication floor and adjusting the height of frame column, the structure system can satisfy the requirement of many building functions. At present the structure system is applied successfully to the multi-layer dormitory, office building, restaurant, high-rise apartment hotel and etc.

\section{The System Saves Material and Energy Consumption, Accords with the Development Trend of Modern Steel Structure}

The structure system adopts modular design, factory production and assembly on spot, the material utilization reaches $98 \%$ meanwhile the energy consumption is much less than that of conventional buildings. It is a kind of green 
technology, a new type of sustainable structure form.

\section{Some Problems Need to Be Solved}

Although the technological superiority is obvious, some problems are still needed to be solved for the promotion and application of such a new kind of assembly truss beam steel frame structural system:

\section{A. Development of Manufacturing and Construction Technology}

The characteristic of industrialized production is conducive to guarantee good performance and high quality for the components and connections of structure, while all of these are based on the precise machining accuracy and good quality of construction and installation. In order to generalize the use of this new kind of structure system, some relative matching technology need to be established, such as component modular manufacturing technology, general connections manufacturing techniques, assembly construction technology, industrialization containment system fast construction technique, etc. At the same time, some corresponding quality control and technical safeguard measures is indispensable.

\section{B. Preparation of Technical Standards and Codes}

For this new kind of structure system, there are no specific technical standards or codes for reference so far. It is a big obstacle for the design, inspection and acceptance of practical engineering. Combining with the development of the related research institutions and enterprises to establish some concrete technical standards and codes is a very urgent task. Only using the standards and codes to guide the design and construction of practical engineering, this new kind of assembly structure system can be got more popularization and application.

\section{Conclusions}

Assembly truss beam steel frame system is a new kind of assembly multi-high rise steel structure. On the basis of detailed analysis for the technology characteristic, the present paper sums up the main technical advantages, points out that such an assembly structure system is a promising structure style. Finally, some problems need to be solved are also put forward for the promotion and application of such a system.

\section{REFERENCES}

[1] N. Mehrotra, M. Syal, and M. Hastak, "Manufactured Housing Production Layout Design," Journal of Architectural Engineering, vol. 11, pp. 25-34, 2005.

[2] N. Sadafi, M. F. M. Zain, and M. Jamil, “Adaptable Industrial Building System: Construction Industry Perspective," Journal of Architectural Engineering, vol. 18, pp. 140-147, 2012.

[3] Y. F. Badir, M. R. Abdul Kadir, and A. H. Hashim, "Industrialized Building Systems Construction in Malaysia," Journal of Architectural Engineering, vol. 8, pp. 19-23, 2002.

[4] M. Gong and W. Zhu, "Green building performance analysis of high-rise residence in steel structure residence system," Advanced Materials Research, vol. 461, pp. 83-87, 2012.

[5] Broad Sustainable Building CO., LTD, "A kind of steel column," Chinese Patent, 202627316U. 2012-12-26.

[6] X. Y. Liu, Y. Q. Wang, Y. J. Shi, and M. Liu, "Finite element analysis of bearing properties of floor structure of precast cold-formed steel building," Journal of Shenyang Jianzhu University, vol. 29, no. 2, pp. 226-232, 2013.

[7] Q. C. Li, G. Liu, A. J. Hu, and D. H. Zhu, "Experimental study on frictional energy- dissipation behavior of bolted steel beam splicing in rigid frame," Building Structure, vol. 41, no. 5, pp. 78-81, 2011.

[8] G. Liu and Y. T. Hu, "Effect of opening methods of slotted hole on seismic performance of steel beam's high-strength bolted splice," Steel Construction, vo1. 26, no. 145, pp. 19-24, 2011.

Zaihua Zhang was born in Hunan, China. He has obtained the bachelor of engineering and M.Sc. degree in civil engineering in 2006 from Civil Engineering College of Hunan University. He is a PhD student of Structural Engineering in Hunan University. His subject area is "The basic theory of steel structure analysis and design"

Xingping Shu was born in Hunan, China. He got B.Sc., MSc, and Ph.D. degree from Hunan University, Civil Eng. Dept. His subject area is "The basic theory of steel structure analysis and design". His current job is Prof. Dr. in Hunan University. 